\title{
Antimicrobial activity of the autochthonous compound Enoxil
}

\author{
Lucian Lupaşcu ${ }^{1}$, Valeriu Rudic ${ }^{1,2}$, Viorica $\operatorname{Cotos}^{3}$, Tudor Lupaşcu ${ }^{4}$ \\ ${ }^{1}$ Institute of Microbiology and Biotechnology of the ASM, Chişinău, Moldavia; \\ ${ }^{2}$ Academy of Sciences of Moldova (ASM), Chişinău, Moldavia; \\ ${ }^{3}$ Hospital of Contagious Diseases "T. Ciorba", Chişinău, Moldavia; \\ ${ }^{4}$ Institute of Chemistry of the ASM, Chişinău, Moldavia. \\ Email: lucian1978@mail.ru
}

Received 24 February 2010; revised 18 March 2010; accepted 31 March 2010.

\begin{abstract}
The paper presents data about the antimicrobial activity of the autochthonous compound of taninic source Enoxil. The minimal inhibitory and bactericidal/fungicidal concentrations were established for some skin and wound infectious agents. It was established, based on Pseudomonas bacteria model, that the Enoxil compound suppress the activity of some important enzymes-a phenomenon that leads to the increase of bacterial sensibility to many tested antibiotics.
\end{abstract}

Keywords: Bacteria; Compound; Tannins; Wound; Infection

\section{INTRODUCTION}

Skin and wound infections, although more characteristic for countries with low economic level and low hygiene standards [1], have lately become a serious concern for highly socio-economically developed countries, as well [2-5]. Of great concern are also the intrahospital plague infections, as they complicate the recovering process, produce anxiety, increase patient's discomfort and may lead to death, being at the same time a serious threat to the medical worker [5,6]. The economical aspects of infections are also considerable [7]. The most frequent microorganisms in the derma or the purulent wound are the gram-positive bacteria Staphylococcus aureus and the gram-negative bacteria Escherichia coli, Pseudomonas aeruginosa [8]. Special attention is paid to pseudomonadic infections as complications of combustions, traumas, tattoo procedures, cellulites, decubital chronic ulcers, foliculitis [9-11].

One of the traditional methods of fighting infections is the use of antibiotics. However, a concerning phenomenon is observed lately in the entire world, including the Republic of Moldova-resistance of microorganisms to these compounds $[12,13]$. A permanent and, often, abusive treatment with antibiotics had as a result the selection of new virulences, aggressive and severe, with a high genetic resistance potential. This situation directs the specialists in the field towards the elaboration of antimicrobial compounds on the basis of novel action mechanisms [14]. Albeit the use of tannin extracts from plants for the treatment of various derma and plagues infections has been known for a long time, these don't exhibit the expected effect for many microorganisms [15-17]. At the moment, the number of efficient medicinal compounds, elaborated on the basis of tannin compounds is quite low, mostly due to the insolubility of many of them in aqueous or alcoholic solutions. The capacity of phenolic (tannin) extracts to disinfect and rapidly treat wounds is based on two fundamental phenomena-antimicrobial and antioxidant activities, determined by a series of mechanisms: capturing of iron ions from the substrate, thus depriving microorganisms of compounds necessary for their physiological activity; their binding to microbial proteins and formation of complexes; capturing of free radicals; absorption of oxygen radicals; inhibition of low density lipoproteins oxidation [18]. It is known that grape seeds are a rich source of so called enotannins-condensed tannins which represent a wide variety of natural substances with polyphenolic structure, remarkable due to the high content of proanthocyanidins [19]. There are enotannins in industrial quantities in the Republic of Moldova. Taking into account that many tannins with antimicrobial properties are insoluble in water, as well as the growing microbial resistance to vegetal tannins, of great potential are researches regarding the possibility of structural modification of enotannins, increase of their oxidation number, in order to increase their efficiency and to use them for the treatment of skin and plague infections.

The objective of present researches was to elucidate the antimicrobial activity of the autochthonous com- 
pound Enoxil of tanninic origin.

\section{MATERIALS AND METHODS}

Research was carried out at the Department of Microbiology, Immunology and Virusology of the State University of Medicine and Pharmaceutics "N.Testemiteanu".

The autochthonous compound Enoxil served as the antimicrobial remedy, obtained by hydro-solubilization of enotannins using chemical and physico-chemical procedures [20]. As microbial cultures, served several pathogens with severe implications in many contagious diseases-bacteria Staphylococcus aureus, Escherichia coli, Salmonella abony, P.aeruginosa, Proteus vulgaris and the fungus Candida albicans.

In order to determine the level of activity of the tested compound, the values of minimal inhibiting concentration (MIC) and the minimal bactericidal/fungicidal concentration (MBC/MFC) were used [21]. As test indices of the action of Enoxil on the P.aeruginosa bacteria, served a range of important biochemical parameters indices of bacterial viability and pathogenicity: synthesis of cytochrome oxidase, citrate reductase, haemolysins, pyocyanin, odour presence, and as the index of sensibility towards antibiotics-zone of inhibition $(\mathrm{mm})$ of the culture, specific to each antibiotic. The sensibility of the P.aeruginosa bacteria was determined using the method of antibiotics diffusion in gelose from roundels [22] that contained the following antibiotics homologated in the Republic of Moldova: cloramfenicol $(30 \mathrm{mkg})$, pefloxaciline $(5 \mathrm{mkg})$, erythromycin $(15 \mathrm{mkg})$, cefuroxim $(30 \mathrm{mkg})$, cefoxitin $(30 \mathrm{mkg})$, cefalotine $(30 \mathrm{mkg})$, piperacillin $(30 \mathrm{mkg})$, imipenem $(10 \mathrm{mkg})$, ciprofloxacin (5 mkg), tobramycin $(10 \mathrm{mkg})$, gentamicin $(10 \mathrm{mkg})$, tetracycline $(30 \mathrm{mkg})$. The standardized nutritive medium Miuller-Hinton was used for testing. The boxes with bacteria and antibiotics were maintained at $37^{\circ} \mathrm{C}$, for 24 hours, with a subsequent determination of the result of antibioticogram.

The acute toxicity research during the enteral administration of the Enoxil compound was made on mouses and white rats. It was established that the 500, 1000 and $2000 \mathrm{mg} / \mathrm{kg}$ body weight doses do not provoke modifications in the animals behaviour and neither their death. The cronical toxicity was established by the administration of the Enoxil in 100 and $300 \mathrm{mg} / \mathrm{kg}$ body weight doses at the male rats during 30 days.

Data were statistically analysed using the soft package STATISTICA 7.

\section{RESULTS AND DISCUSSIONS}

During the research was established that the animals that took the $300 \mathrm{mg} / \mathrm{kg}$ dose were more adinamic and were dead in 5-21 days time, but those administrated the 100 $\mathrm{mg} / \mathrm{kg}$ dose survived. At macroscopical examination of the internal organs were not attested any pathological modifications. After undertaken the cronical toxicity study was established that the Enoxil compound in the $100 \mathrm{mg} / \mathrm{kg}$ dose do not modify esentially the level of creatinin and cholesterol.

Investigations on the action of Enoxil compound on bacteria E.coli, S.abony, S.aureus, P.vulgaris, P.aeruginosa and the fungus C.albicans resulted in the determination of the MIC (Figure 1(a)) and the minimal bactericidal/fungicidal concentration (MBC/MFC) (Figure 1(b)). Thus, Enoxil presents antibacterial, as well as antifungal properties at relatively low concentrations. The minimal

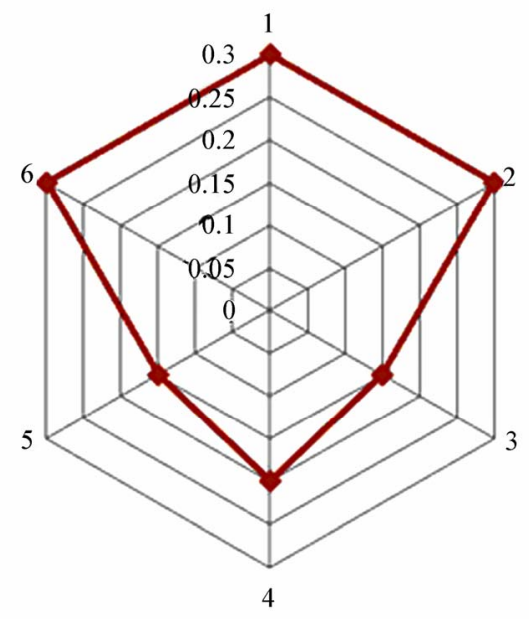

(a)

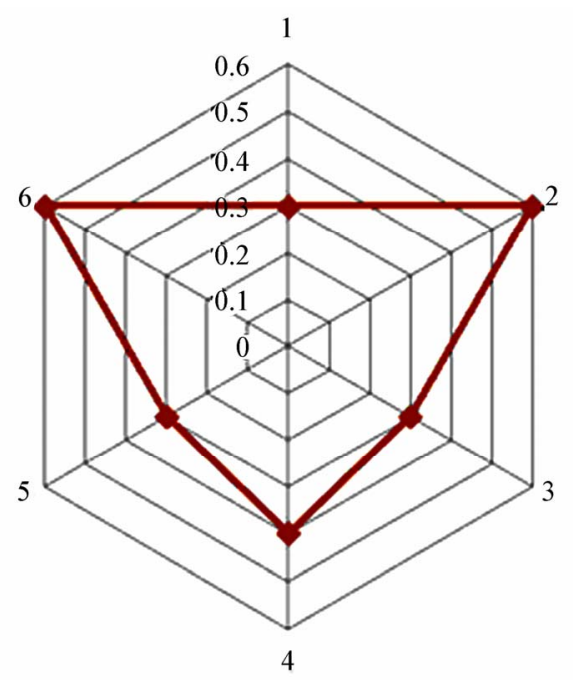

(b)

Figure 1. (a) Minimal inhibiting concentration and (b) Bactericidal/fungicidal of Enoxil for several microorganisms. On the hexagonal perimeter: 1-E.coli, 2-S.abony, 3-S.aureus, 4-P.vulgaris, 5-P.aeruginosa, 6-C.albicans. On the vertical-concentrations, $\%$. 
inhibiting concentration of Enoxil for the tested bacteria was shown to be in the range $0.15-0.3 \%$, while the bactericidal one-in the range $0.3-0.6 \%$. For the fungus C.albicans the minimal inhibiting concentration equals to $0.3 \%$, while the fungicidal one- to $0.6 \%$.

The values MIC and MBC/MFC for the microorganisms taken into the study presented differences of an order of magnitude, except for the E.coli bacteria, when these indexes coincided. As a result of the correlation analysis, it was determined that the degree of dependence ( $r$ ) between MIC and MBC/MFC is significant and positive, equal to 0.66 . Regression analysis, which has a predictive value and represents the mathematical relation of the dependence, demonstrated that its equation is: $\mathrm{y}=$ $0.0923+0.3385 \times(\mathrm{p} \leq 0.05)$.

Data presented in Table 1 shows that under the action of Enoxil at the determined static concentration $(0.15 \%)$ took place the suppression of activities of oxidases, citrate reductases and haemolysin. At the same time, the bacterial culture didn't produce any pyocyanin and indole, and it didn't develop any specific odours. In these conditions, the maintenance of the mobility is a proof of bacteria viability, which reveals the correctitude of the test. Thus, the static concentration of Enoxil produces significant perturbations at the biochemical level inside the bacterial cell, which probably significantly diminishes the capacity of substrates decomposition, as well as its pathogenic potential.

Treatment of the bacterial culture with Enoxil in- creased the sensitivity (S) for the majority of investigated antibiotics, with manifested resistance (R) only for erythromycin and cefalotine (Table 2).

In the case of tetracycline, a reaction of medium sensitivity was observed (RS). In the case of blank, the culture manifested sensitivity only for pefloxaciline and imipenem, while in the case of using Enoxil, the sensibility was exhibited towards the majority of antibiotics, except for erythromycin and cefalotine. It should me mentioned that Enoxil introduced sensibility into the bacteria towards several antibiotics considered inactive for P.aeruginosa, for example cefoxitin. The analysis of the similitude degree of the compounds using the clusterian method of dendrograms construction, demonstrated that the tested antibiotics were distributed in big clusters (Figure 2(a)), quite different, which reveals that

Table 1. Influence of the static concentration of Enoxil on several biochemical and functional indices of the P.aeruginosa bacterium.

\begin{tabular}{lcc}
\hline \multicolumn{1}{c}{ Indicator } & Blank $(+/-)$ & Enoxil $(+/-)$ \\
\hline Oxidase & + & - \\
Citrate reductase & + & - \\
Haemolysin & + & - \\
Indole & - & - \\
Pyocyanin & + & - \\
Odour & + & - \\
Mobility & + & + \\
\hline
\end{tabular}

Table 2. Influence of the static concentration of Enoxil on the sensibility of the culture P. aeruginosa towards several antibiotics.

\begin{tabular}{cccccc}
\hline \multirow{2}{*}{ Nr. } & Antibiotic & \multicolumn{2}{c}{ Untreated culture (blank) } & \multicolumn{2}{c}{ Treated culture } \\
\cline { 3 - 5 } & & Inhibition zone, $m$ m & Reaction & Inhibition zone, mm & Reaction \\
\hline 1 & Cloramfenicol & 0.0 & $\mathrm{R}$ & $26.0 \pm 0.6^{*}$ & $\mathrm{~S}$ \\
2 & Pefloxaciline & $14.0 \pm 0.6$ & $\mathrm{R}$ & $26.3 \pm 0.3^{*}$ & $\mathrm{~S}$ \\
3 & Erythromycin & 0.0 & $\mathrm{R}$ & $13.0 \pm 0.6^{*}$ & $\mathrm{R}$ \\
4 & Cefuroxim & 0.0 & $\mathrm{R}$ & $20.0 \pm 1.2^{*}$ & $\mathrm{~S}$ \\
5 & Cefoxitin & 0.0 & $\mathrm{R}$ & $22.0 \pm 0.6^{*}$ & $\mathrm{~S}$ \\
6 & Cefalotine & 0.0 & $\mathrm{R}$ & 0.0 & $\mathrm{R}$ \\
7 & Piperacillin & 0.0 & $\mathrm{R}$ & $20.0 \pm 1.2^{*}$ & $\mathrm{~S}$ \\
8 & Imipenem & $30.0 \pm 1.2$ & $\mathrm{~S}$ & $29.3 \pm 1.5^{*}$ & $\mathrm{~S}$ \\
9 & Ciprofloxacin & 0.0 & $\mathrm{R}$ & $24.0 \pm 0.6^{*}$ & $\mathrm{~S}$ \\
10 & Tobramycin & 0.0 & $\mathrm{R}$ & $17.0 \pm 1.2^{*}$ & $\mathrm{~S}$ \\
11 & Gentamicin & 0.0 & $\mathrm{R}$ & $16.0 \pm 0.6^{*}$ & $\mathrm{~S}$ \\
12 & Tetracycline & 0.0 & $\mathrm{R}$ & $19.0 \pm 0.7^{*}$ & $\mathrm{R}-\mathrm{S}$ \\
\hline
\end{tabular}

* - difference from the blank with statistic support at $\mathrm{p}<0.05$. 


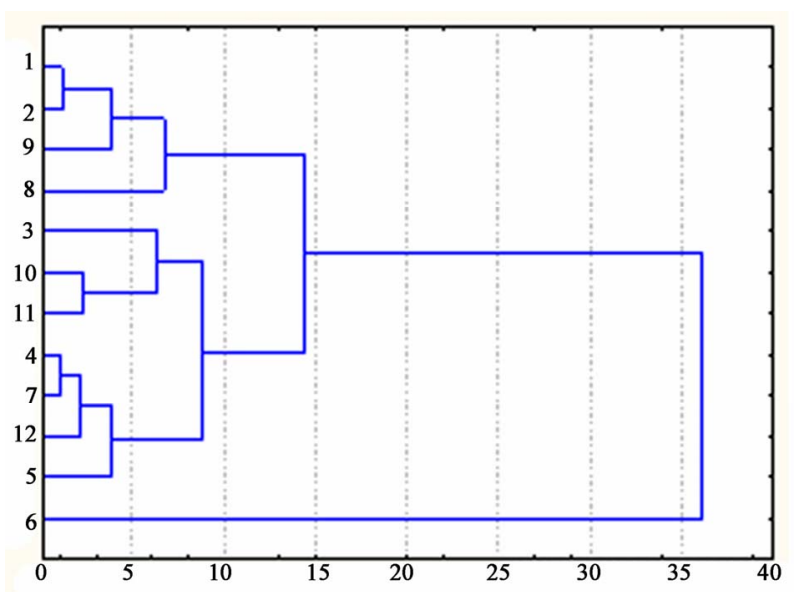

(a)

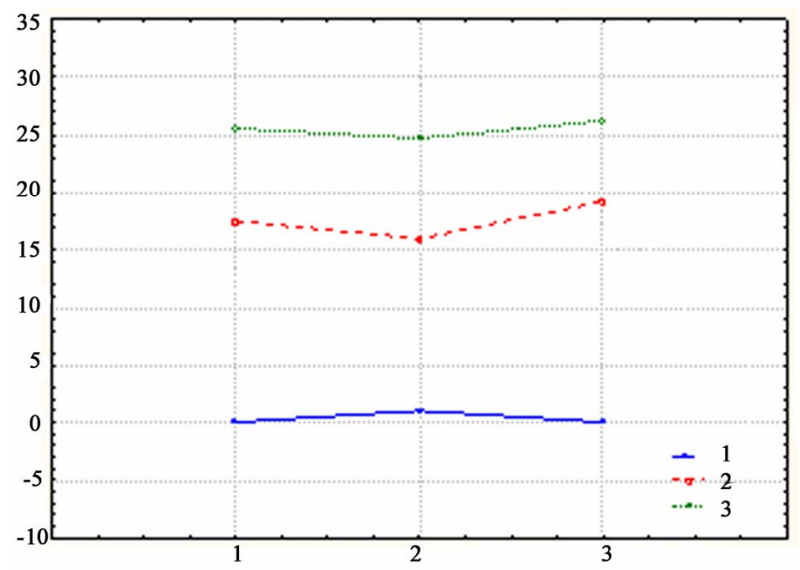

(b)

Figure 2. Clusterian analysis ((a)-construction of the dendrogram; (b)-method of k-means) of antibiotics on the basis of the capacity of suppression of p.aeruginosa strain treated with enoxil $(0.2 \%)$. (a) on the vertical: 1-cloramfenicol, 2-pefloxaciline, 3-erythromycin, 4-cefuroxim, 5-cefoxitin, 6-cefalotine, 7-piperacillin, 8-imipenem, 9-ciprofloxacin, 10-tobramycin, 11-gentamicin, 12-tetracycline. on the horizontal: 0 -40-euclidian distances. (b) on the vertical: 1, 2, 3-clusters of antibiotics. On the horizontal: 1, 2, 3-repeats.

the bacterial stem treated with Enoxil has different reaction towards antibiotics. A significantly different cluster was presented by the compound 6 - cefalotine (one of the most efficient antibiotics in pseudomonadic infections), for which the stem manifested the greatest resistance (inhibition zone: $0.0 \mathrm{~mm}$ ). The lowest is the aggregation degree of clusters, the greatest is antibiotics similitude, on the basis of the inhibition zone (for example, cloramfenicol-1 and pefloxaciline-2). As opposed to the method of dendrograms construction, which is an agglomeration-iterative method and performs objects classification (antibiotics) on the basis of various aggregation levels, the method k-means of clusterian analysis, non-iterative, classifies objects in clusters, determined by the researcher, on the basis of possible effects: low, medium, high, etc. and presents opportunities of high precision [23].

The classification (repartition) of antibiotics on the basis of the action on the P.aeruginosa strain, treated with Enoxil evidenced the existence of clusters with pronounced differences (Figure 2(b)). Through the examination of members (antibiotics) of the 3 clusters, it was determined that cluster 1 was formed by cefalotine alone, for which P.aeruginosa manifested the highest resistance, which was confirmed by the analysis of the repartition dendrogram. The cluster 2, where the antibiotics erythromycin, cefuroxim, piperacillin, tobramycin, gentamicin, tetracycline were distributed, is characterized by their capacity to produce a reaction of medium sensibility, while the cluster 3 - antibiotics cloramfenicol, pefloxaciline, cefoxitin, imipenem, ciprofloxacin - a reaction of strong sensibility.

Thus, if we make abstraction of the antibiotic imipenem, for which the strain presented sensibility in the blank as well, it may be observed that Enoxil induced a reaction of strong sensibility for the majority of antibiotics, among which 3 antibiotics - cloramfenicol, pefloxaciline and cefalotine are not used for the treatment of pseudomonadic infections [24], i.e. are non-specific.

\section{CONCLUSIONS}

The values MIC and MBC/MFC of Enoxil for the investigated microorganisms presented differences of an order of magnitude, except for the bacterium E.coli, for which these indices coincided. It was found that there is a high and positive correlation for $\mathrm{MIC} / \mathrm{MBC}$ during treatment with Enoxil, which makes microorganisms behaviour predictive.

On the model of the P.aeruginosa bacteria it was determined that several of the biochemical mechanisms of suppression of growth and development by Enoxil consist in the inhibition of synthesis of such enzymes, important for the bacterial organism viability, as oxidases, citrate reductases, haemolysins, as well as pyocyanin. This phenomenon influenced most directly the sensibility of the bacteria towards a series of antibiotics used in modern medicine. The compound Enoxil in bactericidal concentrations (MBC- $0.3 \%$ ) may be considered of great potential in the treatment of pseudomonadic infections.

\section{ACKNOWLEDGEMENTS}

The authors are very grateful to Prof. V. Gonciar from the Department of Pharmacology from the State University of Medicine and Pharmacy "N.Testemitanu" who carried out the research on the toxicity of the Enoxil compound. 


\section{REFERENCES}

[1] Dogra, S. and Kumar, B. (2003) Epidemiology of skin diseases in school children: A study from Northern India. Pediatric Dermatology, 20(6), 470-473.

[2] Collier, M. (2002) Wound-bed management: Key principles for practice. Professional Nurse, 18(4), 221-225.

[3] Cooper, R. (2002) Wound microbiology: Past, present, and future. British Journal of Nursing, 11(22), 4-6.

[4] Miller, M. (2001) Wound infection unravelled. Journal of Community Nursing, 15(3), 31-33.

[5] Nosocomial Infection National Surveillance Service (2002) Surveillance of surgical site infection in English hospitals: A national surveillance and quality improvement programme. Health Protection Agency, London.

[6] Singh, N.P., Goyal, R., Manchanda, V., et al. (2003) Changing trends in bacteriology of burns in the burns unit. Burns, 29(2), 129-132.

[7] Prisacari, V. and Paraschiv, A. (2008) Contrubutions in the epidemiological surveillance systems optimization within nosocomial septico-purulent infections of surgical profile. Epidemiology and Microbiology. Mat. Congress VI of Hygienists, Epidemiologists and Microbiologists from the Republic of Moldova, Chişinău, 2, 22-25.

[8] Rodgers, G., Mortensen, J., Fisher, M., et al. (2000) Predictors of infectious complications after burn injuries in children. Pediatric Infectious Disease Journal, 19(10), 990-995.

[9] Gang, R.K., Bang, R.L., Sanyal, S.C., et al. (1999) Pseudomonas aeruginosa septicaemia in burns. Burns, 25(7), 611-616.

[10] Kehheth, T. (2008) Pseudomonas aeruginosa. http://www. textbookofbacteriology.net/pseudomonas.html

[11] Rozhavin, M.A. (1983) Some biological properties of the P.aeruginosa melanin. Journal of Microbiology, in Russian, 1, 45-47.

[12] Valencia, I., Kirsner, R. and Kerdel, F. (2004) Microbiologic evaluation of skin wounds: Alarming trend toward antibiotic resistance in an inpatient dermatology service during a 10-year period. Journal of the Ameri- can Academy of Dermatology, 50(6), 845-849.

[13] Visnevchi, L. and Bradu, V. (2008) Antibiotical microorganisms resistance modification, tested in the microbiological laboratory of PRMC Ungheni. Epidemiology and Microbiology. Mat. Congress VI of Hygienists, Epidemiologists and Microbiologists from the Republic of Moldova, Chișinău, 2, 264-265.

[14] Schwaber, M.J., Cosgrove, S.E., Gold, H.S., et al. (2004) Fluoroquinolones protective against cephalosporin resistance in gram-negative nosocomial pathogens. http://www. medscape.com/viewarticle/466484

[15] Asres, K., Mazumder, A. and Bucar, F. (2006) Antibacterial and antifungal activities of extracts of combretum molle. Ethiopian Medical Journal, 44(3), 269-277.

[16] Santos, S.C. and Mello, J.C.P. (2004) Taninos. Farmacognosia da Planta ao Medicamento, in Portuguese, 5th Edition, Porto Alegre, Florianópolis, 615-656.

[17] Timbola, A.K., Szpoganicz, B., Branco, A., et al. (2002) A new flavonol from leaves of Eugenia jambolana. $\mathrm{Fi}$ toterapia, 73(2), 174-176.

[18] Chung, K., Lu, Z. and Chou, M. (1998) Mechanism of inhibition of tannic acid and related compounds on the growth of intestinal bacteria. Food and Chemical Toxicology, 36(12), 1053-1060.

[19] Kulciţki, V., Vlad, P., Duca, G., et al. (2007) Investigation of grape seed proantocyanidins. Chemistry Journal of Moldova, 2(1), 36-50.

[20] Lupascu, T. and Lupascu, L. (2006) The obtaining procedure of the watersoluble enotannins. Patent Nr. 3125. MD. BOPI: 8.

[21] Andrews, J.M. (2001) Determination of minimum inhibitory concentrations. Journal of Antimicrobial Chemotherapy, 48(1), 5-16.

[22] National Committee for Clinical Laboratory Standards (NCCLS) (2002) Performance standards for antimicrobial susceptibility testing. 12th Informational Supplement M100-S12 NCCLS, Wayne.

[23] Halafian, A.A. (2008) Modern statistical methods of medical research. In Russian, LKI Publishers, Moscow.

[24] Matcovschi, C., Procopisin, V. and Parii, B. (2006) Pharmacotherapeutical guide. Central Printing, Chişinău. 